\title{
TRABALHO E PRAZER: TEORIA, PESQUISAS E PRÁTICAS
}

\author{
Work and Pleasure: Theory, Research and Practices
}

Trabajo y Placer: Teoría, Investigaciones y Prácticas

\section{Travail et Plaisir: Théorie, Recherche et Pratique}

Cicero Simões Borges

Mestrando em Administração pela Universidade Federal Fluminense e Graduado em Administração pela Universidade Federal Fluminense.

Adelaide da Cruz Santos

Mestranda em Administração pela Universidade Federal Fluminense e Graduada em Administração pela Universidade Federal dos Vales do Jequitinhonha e Mucuri.

Recebido em: 12/11/2015 / Revisado em: 19/03/2016 / Aceito em: 24/04/2016

\section{Resumo}

Resenha dos principais estudos apresentados no livro Trabalho e prazer: teoria, pesquisas e práticas. A obra mostra os meandros do trabalho como fonte de prazer e, ao mesmo tempo, sofrimento. Aborda teorias e aplicações práticas, como a psicodinâmica do trabalho, a partir de pontos de vista de pesquisadores de múltiplas áreas do conhecimento.

\section{Abstract}

Summary of the main studies presented in the book Work and pleasure: Theory, research and practices. The work shows the intricacies of work as a source of pleasure and at the same time suffering. It addresses theories and applications of practices such as the psychodynamics of work from the points of view of researchers from multiple areas of knowledge.

\section{Resumen}

Reseña de los principales trabajos presentados en el libro Trabajo y placer: teoría, investigaciones y prácticas. La obra enseña las sinuosidades del trabajo como fuente de placer y al mismo tiempo de sufrimiento. Aborda teorías y explicaciones de prácticas como la psico-dinámica del trabajo partiendo de puntos de vista de investigadores de distintas áreas del conocimiento.

\section{Résumé}

Aperçu des principales études présentées dans le livre Travail et plaisir : théorie, recherche et pratique. L'oeuvre montre la complexité du travail comme une source de plaisir et, en même temps, de souffrance. Elle couvre aussi les théories et les applications des pratiques comme la psychodynamique du travail du point de vue de chercheurs de plusieurs champs de la connaissance.

A frase "vamos deixar o trabalho de lado um pouco" é, atualmente, um excelente exemplo de expressão incapaz de produzir representação mental, porque nunca ou raramente se deixa o trabalho. Ele está permanentemente materializado, por exemplo, nos mais diversos aplicativos que possuímos para nos comunicar. Isso indica apenas a exacerbada demanda de ocupação com o trabalho que se tem na atualidade; cujo suprimento subtrai do trabalhador sua saúde física e mental, 
impedindo-o de manter ou alcançar o status individual de bem-estar. Contrariamente, pode levá-lo ao sofrimento e à doença. A superestrutura criada a partir da Revolução Industrial - ou revolução no mundo do trabalho -, para fazer funcionar as novas formas de produção, invertera a relação trabalhador e objeto, (re)produzindo e naturalizando silenciosamente as consequências negativas, individuais e coletivas dessa inversão. Uma delas é a mutação nos sentidos do trabalhar.

Mas, quais as causas? E as consequências? Existem estratégias para conviver melhor com isso? Se existem, é possível aprimorá-las? Quais soluções podem ser propostas? Para refletir e apresentar respostas tangíveis a questões dessa natureza, a partir da reunião de um grupo de trabalho no XV Simpósio da ANPEPP (Associação Nacional de Pesquisa e Pós-Graduação em Psicologia), surgiu a proposta de um livro tendo por objetivo central apresentar reflexões que contribuam com: os desafios do prazer no trabalho e os avanços teórico-metodológicos da psicodinâmica do trabalho no Brasil.

Portanto a obra Trabalho e Prazer é composta por uma reunião de artigos de professores pesquisadores de diversas universidades do Brasil e componentes daquele grupo de trabalho vinculado à ANPEPP, instituição que realiza pesquisas na área da saúde mental e do trabalho há mais de uma década, e que, a partir de 2010, tem adotado mais especificamente o referencial da psicodinâmica do trabalho para suas pesquisas. Dentre eles, a profa. Dr ${ }^{\mathrm{a}}$. Janine Kieling Monteiro, da UNISINOS; o prof. Dr. Fernando de Oliveira Vieira, da UFF; e a profa. Ana Magnólia Mendes, da UnB.

O livro é dividido didaticamente em três partes, que apresentam pesquisas multidisciplinares em ordem crescente. Inicia apresentando reflexões essenciais à compreensão das pesquisas, por exemplo, a conceituação das ideias de: trabalho, prazer, sublimação, coletivo de trabalho, entre outras. Contextualiza a prática da psicodinâmica do trabalho e aprofunda a discussão da dinâmica da subjetivação através da exploração das conexões afetivas e patologias do trabalho. Ao final, apresenta aplicações em casos brasileiros com a abordagem de impacto, utilidade epossibilidades de ressignificação pela experiência prática das inter-relações de prazer e trabalho.

Destaca-se ainda, nessa obra, a acuidade apresentada pelos diversos autores na elaboração de suas pesquisas, que dialogam com a psicanálise e com a sociologia, possibilitando ao leitor construir visão ampla e diversificada a partir de pontos de vista complementares para um mesmo problema.

A parte I, intitulada "Prazer, sentidos do trabalhar", apresenta desde a conceituação de trabalho, suas relações com o sofrimento e o prazer, até o processo histórico de precarização do trabalho, passando pela discussão sobre o reconhecimento e o processo de sublimação libidinal através da inteligência criativa, utilizada para elaborar a lacuna entre o prescrito e o real.

É demonstrado o processo de subjetivação do trabalhador frente ao real do trabalho, abordando também os processos de sublimação e perlaboração. O reconhecimento e o coletivo de trabalho são apontamentos para a experiência prazerosa no trabalho. Portanto, isso indica ser possível existir prazer no contexto do trabalho precário, encontrado em muitas organizações atualmente. Tais análises tiveram como ponto de partida trabalhos como os de Dejours, para compreender as relações com o sofrimento e o prazer no processo de trabalhar, e da psicanálise em Freud, para explorar a sublimação ressaltando-se a importância de compreender as relações que estruturam a saúde mental do trabalhador.

Expõe que, de maneira equivocada, as situações de alienação se impõem: pela cultura do individualismo, que distancia o sujeito do reconhecimento do outro nas organizações; e pela visão distorcida de que os processos, as normas prescritas e os métodos não apresentam erros intrínsecos, promovendo uma visão inflexível que dificulta o reconhecimento do que é realizado.

Uma importante contribuição dos trabalhos apresentados está na ilustração das possibilidades de transformar o sofrimento em prazer, completando o processo positivo de sublimação através do reconhecimento do que é feito, realizado. Embora a precarização do trabalho seja um fato e haja múltiplos fatores que para isso contribuem, é demonstrado que a maioria deles é paralela aos fatores estruturantes do sistema produtivo capitalista. Entretanto, ao que parece, nem tudo está perdido. A psicodinâmica do trabalho é apresentada como metodologia central para a transformação conforme exemplos dos estudos de caso realizados em território brasileiro.

A segunda parte, "Prazer, (Des)Afetos e Patologias", apresenta reflexões de perspectiva sociológica e psicanalítica discutindo e apresentando conceitos como o de "Ser Desafetado", aquele criado pelas organizações, que não expressa emoções, e as reprime tanto que parece não sentir. O que pode levar à questão do insuportável, condição emocional que pode ser natural, advindo do sofrimento da vida ou pode ser proveniente de uma repressão das condições de trabalho do sujeito.

A partir desses conceitos são aprofundadas outras reflexões que buscam compreender as causas: a) estruturais, como a sedução organizacional, a ideologia da excelência, a cultura do individualismo, o processo de reestruturação produtiva e os mecanismos de controle organizacional; e b) inerentes ao sujeito, como os mecanismos patogênicos individuais do pensamento operatório e auto aceleração que podem transbordar para o ambiente familiar dado ao grau de envolvimento do trabalhador com estes mecanismos. Para isso, há a contextualização do ambiente empresarial e da dinâmica de trabalho precarizado, submetido à lógica econômica a qual se devem subordinar os empregados. A organização sedutora é a instrumentalizadora do prazer, tornando-o uma ferramenta com o objetivo de envolver os trabalhadores, voltando-os para o aumento da produtividade. 
Como consequência tem-se, por exemplo a normopatia, doença fundamentada na banalização do mal, do ilícito, do antiético, do desumano; patologias de sobrecarga no trabalho, como o burnout, karôshi, disfunções musculoesqueléticas (DORT's), e a experiência de prazer ou patologia, que é produto do processo de subjetivação do trabalho. Essas patologias acontecem quando as estratégias individuais e coletivas de defesa para negar o sofrimento proveniente da organização do trabalho e evitar o adoecimento falham.

Diante disso, demonstram algumas propostas que, embora desafiadoras, podem corrigir ou amenizar esse problema nas organizações. Com o fortalecimento do coletivo de trabalho, por exemplo, é possível criar um ambiente cooperativo, com maior possibilidade de reconhecimento. Um ambiente onde o coletivo de trabalho faça uso do espaço público político da organização para que haja trocas respeitando a individualidade de cada sujeito.

A parte final do livro, "Prazer, potência política", compreende as aplicações ou parte prática da obra. Fundamentando-se na psicodinâmica do trabalho, as pesquisas mostram: a) como um ambiente de trabalho que possui conflito entre a cultura patriarcal, hierárquica, colonial e o gerencialismo, voltado para alcance de metas, afasta o servidor do seu trabalho por ter metas e não dispor de um ambiente favorável para alcançá-las, dificultando subjetivação mais saudável; b) que o registro de afastamento por motivos psicológicos, em conformidade com a Classificação de Doenças (CID-10) em uma instituição que possuía o maior índice de afastamento desse tipo era uma das estratégias defensivas dos funcionários frente à sedução organizacional utilizada para implantação do novo modelo de gestão; c) o problema de mau uso da autonomia concedida ao servidor público, que pode se acomodar e gerar sobrecarga nos demais docentes. Essa situação pode acarretar conflitos e sofrimento ao coletivo de trabalho. O clima de competição frente ao produtivismo também foi destacado; d) um ambiente de bastante pressão e inflexível com inúmeros causadores de sofrimento para o coletivo de trabalho. Verificou-se que, dada a demanda exagerada das organizações, a normopatia era uma experiência comum aos funcionários como estratégia de defesa.

Destaca-se a pesquisa realizada no setor bancário, no qual há sofrimento ético vivido pelos funcionários, que intimamente discordam de práticas bancárias que são obrigados a desempenhar, evidências de que a mobilização para o alcance de uma condição diferente de trabalho deve partir não apenas dos trabalhadores bancários, mas também dos sindicatos e da sociedade como um todo, aplicando-se aos outros setores. Também fica evidente que essa é apenas uma pequena parte do problema, já que a pesquisa realizada no setor bancário indica origens muito mais estruturais, como a cultura de baixo aprendizado e práticas políticas.

Ao organizar e reunir diversas pesquisas de alguns dos principais grupos brasileiros debruçados no estudo da psicodinâmica do trabalho, a obra consegue trazer um recorte de conteúdo valioso do momento científico presente da teorização e prática da área abordada. Como limitação percebe-se a abrangência das pesquisas exclusivamente com estudos de casos brasileiros bem específicos, podendo o tema ser ainda enriquecido com experiências envolvendo um maior número de participantes, internacionais inclusive, e comparações entre esses universos particulares de pesquisa, permitindo o avanço da compreensão das possibilidades de prazer no trabalho.

Portanto, se de uma perspectiva das teorias organizacionais, o livro mostra a necessidade de conexão gestão, sujeitos e psicodinâmica do trabalho; de uma perspectiva da psicologia, apresenta novas fronteiras a serem exploradas, novas áreas de atuação, ao apresentar aplicações da psicodinâmica do trabalho.

\section{Referência}

Monteiro, J. K., Vieira, F. O., \& Mendes, A M. (Orgs). (2015). Trabalho \& prazer: Teoria, pesquisas e práticas. Curitiba, PR: Juruá.

\section{Endereço para correspondência}

Cicero Simões Borges

E-mail: cicerosborges@gmail.com

Adelaide da Cruz Santos

End.: Rua Tiradentes, $n^{\circ} 108$ A, apto. 1006, Ingá. Niterói/RJ, CEP: 24210-510

E-mail: adelaidecruz@ig.uff.br 